\title{
Integrated model of stochastic dynamics for control of a socio- ecological-oriented innovation economy
}

\author{
S. Ramazanov', L. Antoshkina², V. Babenko ${ }^{3}$, R. Akhmedov ${ }^{4}$ \\ ${ }^{1}$ Department of Information Systems in Economics, Vadym Hetman National Economic University of Kyiv, Ukraine \\ ${ }^{2}$ Rector, Berdyansk University of Management and Business, Berdyansk, Ukraine \\ ${ }^{3}$ Department of International E-Commerce and Hotel\&Restaurant Business, V. N. Karazin Kharkiv National University, Kharkiv, \\ Ukraine \\ ${ }^{4}$ Department of Information Systems in Economics, Vadym Hetman National Economic University of Kyiv, Ukraine
}

\section{Article Info}

Received Mar 2, 2019

\section{Keyword:}

Dynamic model

Innovative

Nonlinear

Instability

Stochastic

Forecasting

Management

Crises

\begin{abstract}
On the basis of modern mathematical models, methods and information and technologies, for example, an integrated stochastic nonlinear model of manmade processes and objects, suitable for the conditions of systemic crises, were investigated and developed. Considered in this article are some aspects of integration of a lot of domains and sectors of operation of modern complex systems which are functioning and developing in the present-day conditions of instability, crises and nonlinearity. In order to predict the development of the state of an innovation economy, the nonlinear integrated stochastic model of growthing dynamic in the phase space has been investigated and developed. In the article, problem of the optimization of the management of the activity of modern complex systems that develop and function regarding current conditions of the instability are considered. The prospect of further research based on the developed models is to conduct computer experiments and their practical usisng. The development and study of criterias, methods and models for optimal management of man-made objects and the creation of making decision systems based on the proposed integral models in the state space are also promising.
\end{abstract}

\section{Corresponding Author:}

\section{Babenko,}

Department of International E-Commerce and Hotel\&Restaurant Business,

V. N. Karazin Kharkiv National University,

Svobody sq. 4, Kharkiv 61022, Ukraine.

Email: vitalinababenko@karazin.ua

\section{Introduction}

Economic growth can occur extensively, that is, by attracting more resources into production, or intensively, by increasing the efficiency of the use of available resources and introducing the results and achievements of the scientific and technological progress (STP) and development into production.

Extended reproduction based on STP is a more progressive way of ensuring economic growth, that is, an increasingly decisive role in the growth of a national economy is played by the achievements of science and technology embodied in innovations.

It is innovation, as the crucial result of STP, that stimulates the growth of productivity and efficiency of the utilization of production factors, as well as the improvement of the quality and competitiveness of a country's products. Therefore, beginning the middle of the twentieth century, a number of leading countries of the world within the group of developed countries have focused on innovation and establishing innovation economy, combining the intensification of STP with institutional transformations in economy and public administration 
aimed at improving the quality of economic system organization and management.

The development of integrated models based on the use of mathematical models, methods and innovative technologies for the purpose of controlling and forecasting the nonlinear dynamics of ecological-economic and socio-humanitarian systems in the current conditions of crises and instability is a matter of urgent importance. This approach is fully supported by the standpoints of many prominent scholars reflected in the concept of sustainable development, which emerged as a result of the combination of three major models and viewpoints (a three-dimensional model): economic, social and environmental as well as taking into account knowledge, technology and random factors of influence of the environment et cetera $[8,26,32]$ structure of economic growth was made by R. Solou [28] and his followers. At the same time, R. Solow's neoclassical growth model lists STP among exogenous factors, which makes it impossible to explain the nature of the growthing of labor productivity based on this concept.

Understanding STP as a factor of growth and economic development is also characteristic of the founders of the "new theory of economic growthing", P. Romer and R. Lucas [14, 17]. Thus, in the endogenous concepts of economic growth, an increase in labor productivity is associated with an increase in investment into research and development, an increase in the number of researchers and scientists, as well as in investments into human capital. These concepts, including their contemporary interpretations, which will be discussed below, allow us to predict the level of STP and determine its impact on economic growth in the short and the long terms.

Thus, the existing methods of taking STP into account in macromodels can be divided into two classes: endogenous and exogenous. The key difference between endogenous and exogenous concepts consists in the fact that in the former the level of technical progress is defined within the model, while in the latter it is a parameter given from the outside.

Modern models of economic growthing taking into account the possibility of investing not only in physical capital, but also in a number of other important resources and assets, in particular in human and intellectual capital [15].

The solution of these problems requires the use of methods of economic-mathematical modelling of economic growthing taking into account environmental, social and innovation factors. In view of the above, this problem is a topical one. Only the integration of the modeling methods of socio-economic, ecological, cultural and spiritual and other processes will ensure the stability and viability of the whole system $[23,26]$ The matter of the impact of knowledge and scientific potential on the economy is scrutinized in the works of V.M. Heets and others $[8,9]$ investigated the role of innovation in economic development. Methods of accounting for STP in aggregated economic models have been described by S.A. Ayvazyan, M.Yu. Afanasyev, V.A. Rudenko, G.B. Kleiner $[1,10]$ and others. The problems of mathematical modeling of the mutual influence of the economic system and ecology are dwelt upon by a large cohort of foreign scientists such as D. Ford, V.Leontiev [13], J. Murakami, Y. Tsukui, W. A. Brock, D. Hsieh [5, 31], O.Tahvonen and J.Kuuluvainen [30]. The most comprehensive is the model developed by Ya.Ya.Vagapova [32] which is the description of the national economy through a system of nonlinear differential equations based on the model of A.N. Moiseev [17] and V.Babenko [2, 30].

As it stems from the foregoing, in modern scientific literature, the integral and aggregated stochastic models of economic growthing and economic development with production, $R \& D$ and education sectors that take into account social, ecological innovation and other factors, are not yet presented.

It is also noteworthy that in present-day complicated conditions of instable development of modern economy, a need arises to revisit the problems of modeling, forecasting and effective management. This is due to the growing impact of the globalization processes, risk, uncertainty and factors on the economy as well as on the performance of the individual regions and countries. Existing methods and forecasting models rely heavily on the use of econometric models.

Therefore, the development and research of integrated models based on the use of mathematical models, methods and innovation technologies with the aim of forecasting nonlinear stochastic dynamics of ecologicaleconomic and socio-humanitarian systems in the current conditions of risks and uncertainty is an urgent issue.

\section{Purpose Statement}

The problem of forecasting, modeling, managing and making decisions in the socio-ecological-economic systems and in science on the whole is central and relevant. The purpose of this work also consists in the development and research of an integrated socio-ecological and economic nonlinear stochastic model of the dynamics of man-made objects and processes for forecast and optimal control in an innovation economy. 
The paper is based on the analysis of modern methods of stochastic dynamic modeling and forecasting of various systems and processes and is a development of some research results of the first author $[11,20,21,26]$.

\section{Results and discussion}

Proposed herein is an overview and analysis of some results received by several authors over the past few years concerning macro- and micro-modeling of the stochastic dynamics of socio-economic, innovative and humanitarian systems and processes that function and develop in complicated conditions of crises and instability.

The development of dynamic models of complex systems and the solution of the tasks of optimal and forecasting control of such systems remains a topical area of research in modern science and practice with vistas for application in various fields. A characteristic feature of complex dynamic systems is their inherent problems of temporary failure of applied managerial principles and structural disproportion. To the examples of nonlinear dynamic systems with such structure belong the systems of sustainable development of regions and countries.

The concept of the sustainable development of the state as a whole and of individual regions makes it possible to ensure a stable and balanced development of the three areas of life: ecological social and economic, incorporating the principles of economic efficiency, social security and environmental safety into a holistic system.

\section{Integration Models of Nonlinear Stochastic Dynamics in Innovation Economy}

1. Model of the General Production of Industrial Sector

$$
Y_{0}(t)=Y(t)+Z(t), Y(t)=C(t)+I(t), I(t)=\rho(t) Y(t),
$$

where $Y_{0}(t)$ is the total output; $\rho(t)$ is the rate of accumulation: $0 \leq \rho(t) \leq 1, Z(t)$ is the volume of pollution ("malicious" output).

The integral output/outcome model in respect of all capital (resources) can be defined as, for example, in case of multiplicative dependence, the production and technological function (PTF) and will look like this:

$$
Y(t)=A(t) K^{d_{1}}(t) L^{d_{2}}(t) H^{d_{3}}(t) N^{d_{4}}(t) \Phi^{d_{5}}(t) S^{d_{6}}(t) I^{d_{7}}(t) .
$$

The following denotations are used here: $\mathrm{K}$ is physical capital, $\mathrm{L}$ is labor, $\mathrm{H}$ is human capital, $\mathrm{S}$ is social capital, $\mathrm{F}$ is financial capital, $\mathrm{N}$ are natural resources (land, water, etc.), $\mathrm{A}(\mathrm{t})$ is function level scientific and technological and technological development, for example, where $A(t)=a[T(t)]^{d}$ is the volume of innovative technologies (resources).

In the general case, the integral output can be represented as a nonlinear function:

$$
Y(t)=F[K(t), L(t), H(t), N(t), \Phi(t), S(t), I(t) ; \vec{c}]
$$

Private variants of the PTF model. The Mankiw-Romer-Weil model is an alternative to accounting for human $H(t)$ capital in the production function, along with physical capital $K(t)$ labor $L(t)$ and natural resources $R(t)$ is $Y(t)=K^{\alpha}(t) \cdot H^{\beta}(t) \cdot[A(t) \cdot L(t)]^{1-\alpha-\beta}$, where $\alpha, \beta>0, \alpha+\beta<1 ; A(t)$ is the function / indicator of technological and scientific progress. We will notice that $\alpha$ is the indicator of elasticity, the share of capital, which is secured by increasing investment; is similarly determined or given $\beta$.

Release model for three assets:

$$
Y(t)=A \tau(t)\left[\left(1-\alpha_{K}^{1}(t)-\alpha_{K}^{2}(t)-\alpha_{K}^{3}(t)\right) K(t)\right]^{\alpha_{1}}\left[\left(1-\alpha_{L_{2}}^{1}(t)-\alpha_{L_{2}}^{2}(t)\right) L_{2}(t)\right]^{\alpha_{2}}+\sigma_{Y}(Y, t) e_{Y}(t),
$$

where $Y(t)$ is the volume of "useful" output; $K(t)$ is the volume of physical capital; $L_{2}(t)$ is the volume of unskilled workforce (more precisely - labor force with relatively low qualification); $\tau(t)$ is the index of PTF, depending on the volume of advanced production technologies used in production, for example, $\tau(t)=[w(t)]^{d}, \quad$ where $\alpha_{K}^{1}(t), d=$ const $\alpha_{K}^{2}(t), \alpha_{K}^{3}(t)$ is the share of the use of physical capital in the sectors of R\&D, environmental and social, respectively, and $0 \leq \alpha_{K}^{1}(t)<1,0 \leq \alpha_{K}^{2}(t)<1,0 \leq \alpha_{K}^{3}(t)<1$ and $0 \leq \alpha_{K}^{1}(t)+\alpha_{K}^{2}(t)+\alpha_{K}^{3}(t)<1 ; \alpha_{L_{2}}^{1}(t)$ and $\alpha_{L_{2}}^{2}(t)$ are the shares of using of the volume of unskilled labor in the ecological and social sectors $0 \leq \alpha_{L_{2}}^{1}(t)<1,0 \leq \alpha_{L_{2}}^{2}(t)<1,0 \leq \alpha_{L_{2}}^{1}(t)+\alpha_{L_{2}}^{2}(t)<1 ; \alpha_{1}, \alpha_{2}$ are the indicators of the measure of production function (elasticity of the output on $K(t)$ and $L_{2}(t)$ ); $0 \leq \alpha_{1} \leq 1$, $0 \leq \alpha_{2} \leq 1, \quad A$ is scale parameter: $A>0,\left\{e_{Y}(t), t \in T\right\}$ is continuous-time white noise, $\sigma_{Y}(Y, t)$ is the 
volatility factor. Here $L(t)=L_{1}(t)+L_{2}(t)$ is the total number of employees.

The output growth depends on the initial capital stock and the random component proportional to its volume. It is assumed that the average stock of capital for this period is determined on the basis of its retirement at a fixed rate. Then the equation of increase in output can be written in the following form [33-35].

$$
d Y(t)=A(t) K(t) d t-\alpha K(t) d t+A(t) K(t) d W_{Y}(t),
$$

where $d Y(t)$ is the growth of gross output for the period $[t, t+d t]$; $\alpha$ is a fixed rate of capital retirement; $d W_{Y}(t)$ is the increment of the Wiener random process with the mean, equal to zero, and dispersion $d t$.

We will notice that in the model (9), as well as in models of social and environmental development, the volume of skilled labor is $L_{1}(t)$ clearly not present. However, on the efficiency of growth and development of production, it affects, but indirectly, that is, for example, through the index and level of scientific, technical and innovative development. This is shown below.

\section{Equation of Capital Dynamics}

The capital model is a model of economic growthing. Mathematical formalization comes from the works of Solow, Sven, Ramsey. Detailed construction of the model is described in $[6,10,34,38]$.

The final model is written as follows:

$$
\frac{d}{d t}[K(t)]+\alpha K(t)=I(t)-C(t)-D(t)-B(t)-\alpha K(t) W_{K}(t), K(0)=K_{0},
$$

where $K(t)$ is capital, $C(t)$ is the volume of consumption, $I(t)$ is investment, $R(\mathrm{t})$ are other resources, $D(t)$ monitoring and reduction costs of pollutants, $B(t)$ - cost of hazard and stable development, $\alpha$ is a fixed rate of capital retirement.

For example, $I(t)=e^{\omega t} F(K(t), L(t), R(t)), \mathrm{R}(\mathrm{t})$ are auxiliary (concomitant) resources, and parameters $\alpha$ is the rate of depreciation $\omega$ is the pace of technological progress. $F$ is the function of production. It with constant elasticity of substitution (SEC) is used most frequently:

$$
F(K, L, R)=\left[\beta_{1} K^{\frac{\delta-1}{\delta}}+\beta_{2} L^{\frac{\delta-1}{\delta}}+\beta_{3} R^{\frac{\delta-1}{\delta}}\right]^{\frac{\delta}{\delta-1}} .
$$

The simple form of recording of capital dynamics in a determined case is as follows:

$$
\frac{d}{d t}[K(t)]+\alpha K(t)=\rho(t) Y(t) \quad \text { or } \quad \dot{K}(t)=-\alpha K(t)+\rho(t) Y(t),
$$

where $\alpha$ is the rate of retirement of physical capital $\alpha \geq 0, \rho(t)$ is the share of investments in the output.

\section{Equation of Labor Dynamics}

In the labor model, traditionally assumed is the exponential change in labor resources, that is, $L(t)=L_{0} \exp (\gamma t), L_{0} \equiv L\left(t_{0}\right)$, where $\gamma$ is the parameter of the pace of growth, that is $\dot{L}=\gamma L$. This model of unlimited labor force growthing is not always reflected in practical application.

However, ragarding the "saturation" effect there is a more realistic model of the dynamics of labor resources (LR) in the form of a logistic equation (that is, the Ferghülst's equation): $\dot{L}(t)=\gamma L(t)\left(1-\frac{L(t)}{L_{\max }}\right)$, where $L_{\max }$ is

the maximum permissible amount of LR (the maximum permissible number of employees).

The mini model of the functioning and development of economy will have the following form:

$$
\begin{aligned}
& Y(t)=F[K(t), L(t), R(t)], \quad C(t)=(1-\alpha) Y(t), \\
& \dot{K}(t)=-\alpha \mathrm{K}(\mathrm{t})+\rho \mathrm{Y}(\mathrm{t}), K\left(t_{0}\right)=K_{0}, \\
& \dot{L}(t)=\gamma L\left(1-L / L_{\max }\right), \quad L\left(t_{0}\right)=L_{0} .
\end{aligned}
$$

where $K_{0}$ is the initial volume of fixed assets, $L_{0}$ is the initial number of labor resources.

Thus, we have a nonlinear dynamic model [26]:

$$
\left\{\begin{array}{l}
\dot{k}(t)=\alpha f(k)-\gamma(1-\eta(t)) k(t), \quad k\left(t_{0}\right)=k_{0}, \\
c(t)=(1-\alpha) f(k), \\
\dot{\eta}(t)=\gamma \eta(t)(1-\eta(t)), \quad \eta(t) \equiv L(t) / L_{\max }, \\
\eta\left(t_{0}\right)=L_{0} / L_{\max } .
\end{array}\right.
$$


Following the logic of modeling, an expanded model of labor resources can be represented by one of the following types:

$$
\begin{gathered}
\dot{L}(t)=\gamma L(t)-\gamma_{Z} Z(t)+\gamma_{C} C(t), \dot{L}(t)=\gamma L(t)\left(1-\frac{L(t)}{\widetilde{L}^{0}(Z, C)}\right), \\
\dot{L}(t)=\gamma L(t) \ln \left(\frac{\widetilde{L}^{0}(Z, C)}{L(t)}\right), L(0)=L_{0} .
\end{gathered}
$$

In the first equation of the constants $\gamma_{Z}, \gamma_{C}$ characterize the change in population (including in connection with changes in mortality, fertility and migration) due to the ecological situation and the level of consumption in the region. In the second and third ones, the function determines the $\tilde{L}^{0}(Z, C)$ change of the upper limit of the number of the entire working population of the region.

A separate problem is to determine the type of the function $\tilde{L}^{0}(Z, C)$.

Dynamics of all labor resources $(L R)$. Let us now consider the dynamics of all labor resources, that is, $L(t)=L_{1}(t)+L_{2}(t)$, where $L_{1}(t)$ and $L_{2}(t)$, respectively, are the volume of skilled and unskilled labor capital, i.e. labor resource.

The growth of the volume of skilled labor $L_{1}(t)$ is modeled endogenously, while the increase in the volume of unskilled labor $L_{2}(t)$ is determined by an exogenous given: $\dot{L}_{2}(t)=\gamma L_{2}(t)$, where $\gamma$ is the growth rate of the number of labor resources (constant $\gamma \geq 0$ ). The modified logistic model is also considered here.

Assume that $\alpha_{L_{1}}^{1}(t)$ is the share of skilled labor employed in the R\&D sector, and $0 \leq \alpha_{L_{1}}^{1}(t) \leq 1$, and $\alpha_{L_{1}}^{2}(t)-$ is the share of the skilled labor force (human capital) employed in education, and $0 \leq \alpha_{L_{1}}^{2}(t) \leq 1$. Let us note that the condition $0 \leq \alpha_{L_{1}}^{1}(t)+\alpha_{L_{1}}^{2}(t)<1$ makes the presence of skilled workforce $L_{1}(t)$ in $L(t)$ possible.

So

$$
L(t)=\left(1-\alpha_{L_{1}}^{1}(t)-\alpha_{L_{1}}^{2}(t)\right) L_{1}(t)+L_{2}(t)
$$

Thus, we arrive at the fact that dynamics is derived from the ratio:

$$
\frac{d}{d t}\left[L_{2}(t)\right]-\gamma L_{2}(t)=-\frac{d}{d t}\left[\left(1-\alpha_{L_{1}}^{1}(t)-\alpha_{L_{1}}^{2}(t)\right) L_{1}(t)\right]+\gamma\left(1-\alpha_{L_{1}}^{1}(t)-\alpha_{L_{1}}^{2}(t)\right) L_{1}(t)+\sigma_{L_{2}}\left(L_{2}, t\right) e_{L_{2}}(t) .
$$

Here $\left\{e_{L_{2}}(t), t \in T\right\}$ is continuous-time white noise, $\sigma_{L_{2}}\left(L_{2}, t\right)$ is the volatility factor.

However, despite the presence of skilled labor $L_{1}(t)$, it $L(t)$ does not affect the efficiency of output in the production, social and environmental sectors; therefore, in these sectors, no difference is drawn between qualified and unskilled labor and for the sake of simplicity, the value $L(t)$ hereafter is called the volume of unqualified labor force.

\section{Equation of Natural Resources Dynamics}

Let $\mathrm{R}(\mathrm{t})$ be auxiliary (concomitant) resources. Models of natural resources consist of two subsystems. This is preconditioned by the presence of two types of resources: non-renewable and renewable.

For the modeling of renewable resources, models are employed that are similar to labor models, that is, the model of Malthus, the model of the Ferghülst, the model of the Gompertz, the model of the Monoda, also the Lotka-Volterra model with ragarding the dynamics of two mutually influential resources $[23,26]$.

Accounting for the actions of other subsystems of the economic and socio-ecological model will lead to the expansion of a typical model of renewable resources. Such an extension can be made by adding additional variables to the model:

$$
\frac{d}{d t}[R(t)]=\gamma_{R} R(t)+\gamma_{K} K(t)-Y(t)-\gamma_{L} L(t)+\sigma_{R}(R, t) e_{R}(t), R(0)=R_{0} .
$$

Here $\left\{e_{R}(t), t \in T\right\}$ is continuous-time white noise, $\sigma_{R}(R, t)$ is the volatility factor.

A non-renewable resource model, unlike the previous model, will not include a regeneration clause $\left(\gamma_{R} R(t)\right)$, but will take into account the exploration of new fields:

$$
\dot{R}(t)=d(K(t), L(t), R(t))+\gamma_{K} K(t)-\gamma_{L} L(t)-Y(t), R(0)=R_{0},
$$

$d(K(t), L(t), R(t))$ is a function that determines the total amount of expenditures for the exploration of natural resources depending on the capital expenditures $K(t)$ and the involved labor $L(t)$. 
5. Equation of the Dynamics of the Potential of the R\&D Sector:

$$
\frac{d}{d t}[\dot{\phi}(t)]-\delta_{\phi} \phi(t)=G[\phi(t)]^{\gamma_{1}} \cdot\left[\alpha_{L_{1}}^{1}(t) L_{1}(t)\right]^{\gamma_{2}} \cdot\left[\alpha_{K}^{1}(t) K(t)\right]^{\gamma_{3}}[s(t)]^{\gamma_{4}}+\sigma_{\phi}(\phi, t) e_{\phi}(t),
$$

where $\phi(t)$ is the stock of knowledge and technology in the economy - the number of inventions that have not lost their validity to year $t ; \dot{\phi}(t)$ is an increase in the stock of knowledge per time unit - the number of new inventions per year $t$ less outdated ones; $L_{1}(t)$ is the volume of qualified (more precisely, highly qualified) labor (skilled labor taking into account qualifications, that is, the product of the number of skilled workers and the level of skills of the average employee $h(t)$, i.e. $\left.h(t) L_{1}(t)\right) ; s(t)$ - social index; $\delta_{\varphi}$ - the pace of knowledge release due to their aging $\delta_{\varphi}>0 ; \alpha_{L_{1}}^{1}(t)$ is the share of skilled labor employed in the R\&D sector $0 \leq \alpha_{L_{1}}^{1}(t) \leq 1 ; \gamma_{1}, \gamma_{2}, \gamma_{3}$ are power parameters: $0 \leq \gamma_{1} \leq 1, O \leq \gamma_{2} \leq 1,0 \leq \gamma_{3} \leq 1$; $G$ is a scale parameter: $G>0$. Here $\left\{e_{\phi}(t), t \in T\right\}$ is continuous-time white noise, and $\sigma_{\phi}(\phi, t)$ is the coefficient of volatility.

6. The Equation of the Dynamics of the Volume of Qualified Workforce in the Education Sector:

$$
\frac{d}{d t}\left[L_{1}(t)\right]-\delta_{L_{1}} L_{1}(t)=D[\phi(t)]^{\eta_{1}} \cdot\left[\alpha_{L_{1}}^{2}(t) L_{1}(t)\right]^{\eta}{ }^{\eta}+\sigma_{L_{1}}\left(L_{1}, t\right) e_{L_{1}}(t)
$$

where $\dot{L}_{1}(t)$ is the increase in the volume of skilled labor per time unit (the difference between the newly created skilled labor and its retirement); $\alpha_{L_{1}}^{2}(t)$ is the share of the volume of qualified workforce employed in education $0 \leq \alpha_{L_{1}}^{2}(t) \leq 1, \quad 0 \leq \alpha_{L_{1}}^{1}(t)+\alpha_{L_{1}}^{2}(t) \leq 1 ; \quad \delta_{L_{1}}$ is the redundancy rate of skilled labor due to the termination of active operations by the carrier of qualifications $\delta_{L_{1}}>0 ; \eta_{1}, \eta_{2}$ are power parameters: $O \leq \eta_{1} \leq 1,0 \leq \eta_{2} \leq 1$; $D$ is the scale parameter: $D>0$. Here, $\left\{e_{L_{1}}(t), t \in T\right\}$ is continuous-time white noise, and $\sigma_{L_{1}}\left(L_{1}, t\right)$ is the volatility factor.

7. Model of the Dynamics of the Total Volume of Pollution $Z(t)$

General presentation form:

$$
\frac{d}{d t}[Z(t)]+g(Z(t))=f^{*}(c, K, L, R)(1-\eta c)+\sigma_{Z}(Z, t) e_{Z}(t), Z(0)=Z_{0},
$$

where $\mathrm{Y}$ is the volume of "useful" output, $\mathrm{K}$ is capital, $\mathrm{L}$ is the number of employees (volume of work), $c$ is the volume of consumption, $Z$ is the volume of contaminants ("harmful" output), $L$ stands for investments, and $\mathrm{R}$ are other resources.

Whereas the increase (growth) of pollution is equal to the difference between the volume of the abatement and the volume of the destroyed pollution due to direct control of it and the result of natural decline (assimilation), the dynamics of pollution in general can be described by the following differential equation: $\frac{d}{d t}[Z(t)]=Z^{+}-Z^{-}$, where for a technogenic object (TO): $Z^{+}=\not f(k), Z^{-}=\lambda(1-\alpha-\beta) f(k)+\delta z$ and for a technogenic regional economy as a whole (in case of mutual TO independence): $Z^{+}=\sum_{1}^{n} \gamma_{i} f_{i}\left(k_{i}\right), \quad Z^{-}=\lambda \sum_{1}^{n}\left(1-\alpha_{i}-\beta_{i}\right) f_{i}\left(k_{i}\right)+\delta z$

Ecological index equation:

$$
\frac{d}{d t}[z(t)]-\delta_{z} z(t)=E[\phi(t)]^{v_{1}} \cdot\left[\alpha_{L}^{1}(t) L(t)\right]^{v_{2}}\left[\alpha_{K}^{2}(t) K(t)\right]^{v_{3}}+\sigma_{Z}(Z, t) e_{Z}(t),
$$

where $z(t)$ is the ecological index; $\dot{z}(t)$ is the growth of the ecological index per time unit; $\delta_{z}$ is the rate of reduction of the ecological index due to environmental pollution $\delta_{z}>0 ; v_{1}, v_{2}, v_{3}$ are power parameters: $0 \leq v_{1} \leq 1, O \leq v_{2} \leq 1,0 \leq v_{3} \leq 1 ; E$ is the scale parameter: $E>0$.

8. Social Index Equation: 


$$
\frac{d}{d t}[s(t)]-\delta_{s} s(t)=H[\phi(t)]^{\nu_{1}} \cdot\left[\varepsilon_{L}^{1}(t) L(t)\right]^{\nu_{2}} \cdot\left[\varepsilon_{K}^{2}(t) K(t)\right]^{\nu_{3}} \cdot\left[\varepsilon_{z}^{3}(t) z(t)\right]^{\nu_{4}}+\sigma_{s}(s, t) e_{s}(t)
$$

where $\dot{s}(t)$ is the growth of the social index per unit hour $\delta_{s}$ is the rate of decline of the social index in connection with the increase of population morbidity, shortening the longevity, increase of the degree of societal stratification and others $\delta_{s}>0 ; v_{1}, v_{2}, v_{3}, v_{4}$ are power parameters of elasticity: $0 \leq v_{1} \leq 1$, $0 \leq v_{2} \leq 1,0 \leq v_{3} \leq 1,0 \leq v_{4} \leq 1, H$ is the scale parameter: $H>0$.

We will notice that the state of the social domain is also contingent upon the ecological state.

\section{Equation of the $R \& D$ Index ( $R \& D$ Factor)}

which increases the efficiency of labor and capital use in production $\tau(t)$ :

$$
\frac{d}{d t}[\tau(t)]+\delta_{\tau} \tau(t)=B\left[\dot{\phi}(t)+\delta_{\phi} \phi(t)\right]^{\beta_{1}}\left[\dot{\sigma}(t)+\delta_{\sigma} \sigma(t)\right]^{\beta_{2}} \bullet\left[\dot{s}(t)+\delta_{s} s(t)\right]^{\beta_{3}}\left[\dot{z}(t)+\delta_{z} z(t)\right]^{\beta_{4}}
$$

where $\dot{\tau}(t)$ is the growth of the R\&D index, caused by a change in the number of advanced production technologies used in production, per time unit, $\delta_{\tau}$ is the rate of reduction of the STP index in connection with the outdating of advanced production technologies $\delta_{\tau}>0 ; \beta_{1}, \beta_{2}, \beta_{3}, \beta_{4}$ are power parameters: $0 \leq \beta_{1} \leq 1$, $0 \leq \beta_{2} \leq 1,0 \leq \beta_{3} \leq 1, O \leq \beta_{4} \leq 1 ; B$ is the scale parameter: $B>0$.

Note that $\tau(t)$ is the index of STP dependent on the number of advanced production technologies $w(t)$ that are utilized in production, for example, $\tau(t)=[w(t)]^{d}$, where $d$-const.

10. Dynamics Model of Investment I $(t)$

If, for example, the output is defined as $Y=F(K, L), Y=I+C$, that is, the modified model of fund dynamics ragarding the delay of investment flows (with a distributed lag and when the functions of the nucleus $h(t-\tau)=h_{0} \exp (-r(t-\tau))$, that is, for a stationary case), will adhere to the following form [28].

$$
\begin{gathered}
\left\{\begin{array}{l}
\dot{K}=-\mu K+I_{h}(t)-C(t)-D(t), K(0)=K_{0}, \\
\dot{I}_{h}=-r I_{h}+h_{0} I_{0}, I_{h}\left(t_{0}\right)=h_{0} I\left(t_{0}\right) .
\end{array}\right. \\
\left\{\begin{array}{l}
\dot{k}=-(\mu+v) k+i_{h}(t), k(0)=k_{0}, \\
\frac{d i_{h}}{d t}=-(r+\mu+v) i_{h}+h_{0} \rho f(k), i_{h}(0)=i_{h 0}, \\
c=(1-\rho) f(k),(\rho \equiv \alpha) .
\end{array}\right.
\end{gathered}
$$

At the same time, we notice that the flow of investments is also a stochastic process. Here, as before: $C$ denotes the volume of consumption, $D$ are the costs of monitoring and pollution reduction efforts.

Equation (11) is the basic dynamic model of a controlled economic system, and as a controlling variable, one can take specific consumption $c(t)=C(t) / L(t)$ or a rate of accumulation, and the state variable $-k(t)-$ is capital intensity, that is, $k(t)=K(t) / L(t)$.

\section{Model of Consumption Dynamics}

In analyzing and constructing the consumption trajectory we assume that the growth of consumption in the period $[\mathrm{t}, \mathrm{t}+\mathrm{dt}]$ can be defined as follows [33]:

$$
d C(t)=A(t) K(t) d t-(1-\alpha) K(t) d t+A(t) K(t) W_{C}(t) .
$$

The proposed model includes stochastic constraints constructed in view of the conditions of the basic dynamic model of the general equilibrium by way of adding a random variable. Another approach to modeling the relationship between consumption and investment under uncertainty conditions involves the partitioning of risk assets and the simulation of their returns in the form of a random variable.

Random processes ragarding the equations of the system are the increments of the Wiener processes, distributed under the normal law with the average equaling zero, and a dispersion being proportional to the duration of a given time interval. Using the indicated property of the increments of random Wiener processes and employing the Euler-Maruyama method, we can construct a discrete approximation of the stochastic equations of the system in the form of linear recurrence relations. At the same time, the corresponding recurrence relations, which are the discrete approximation of system constraints, are written as follows: 


$$
\begin{aligned}
& Y_{t+\Delta}=Y_{t}+\left(A_{t}-\alpha\right) K_{t} \Delta+A_{t} K_{t} \sigma_{K} \Delta \xi_{t}, \\
& K_{t+\Delta}=K_{t}+\left(\left(A_{t}-\alpha\right) K_{t}-C_{t}\right) \Delta+K_{t} \sigma_{K} \Delta \xi_{t}, \\
& C_{t+\Delta}=C_{t}+A_{t} K_{t} \Delta-(1+\alpha) K_{t} \Delta+A_{t} K_{t} \sigma_{K} \Delta \xi_{t},
\end{aligned}
$$

where $\Delta$ is the step of the temporary lattice, on which we will perform calculations in simulation mode; $\xi_{\mathrm{t}}$ is the realization of a random variable that obeys the normal standard law with the average equaling zero and a dispersion equaling one.

\section{Variant Criteria for Optimal Management}

The criterion for the selection of an ecological and economic development strategy:

$$
M[\Phi(C, Y, D, B)] \rightarrow \max
$$

where $\Phi(C, Y, D, B)$ is the welfare function, and $\mathrm{M}$ is a symbol of mathematical expectation.

Thus, we obtain a optimization hierarchical model of the system in the following form:

$$
\{\mathrm{M}\{Z\} \rightarrow \min , \mathrm{M}\{K\} \rightarrow \max , \dot{Z}=\chi(Z, K, L, R, c), \dot{K}=\phi(K, L, R, c) .
$$

In the case of the "small" integral control model, the utility function (UF) is a function of the parameters or variables $\tilde{u}\left(\alpha_{1}, \alpha_{2}, \alpha_{3}, \alpha_{4}\right)$, where $\left\{\alpha_{k}(t), k=1, \ldots, 4\right\}$ are the shares of non-production, environmental, $\mathrm{R} \& \mathrm{D}$, security, innovation and information technology etc. costs, and the criterion of optimality is then this relation:

$$
\Lambda(c, k, z, L, \tau, S)=\int_{t_{0}}^{T} \tilde{u}\left(\alpha_{1}, \alpha_{2}, \alpha_{3}, \alpha_{4}\right) \exp (-\theta t) d t \rightarrow \max _{\left\{\alpha_{i}\right\} \in \tilde{\Omega}} .
$$

To solve the problems of ecological and economic management (EEM) on the basis of cited stochastic and deterministic models, one can use known classical methods of optimal control with constraints [28].

In general, the optimization criterion can be represented as:

$$
\Lambda(\vec{a})=\int_{t_{0}}^{T} \tilde{u}\left(\alpha_{1}, \alpha_{2}, \alpha_{3}, \alpha_{4}, \ldots\right) \exp (-\theta t) d t \rightarrow \max _{\left\{\alpha_{i}\right\} \in \tilde{\Omega}} .
$$

It requires even more integration of models and criteria (and limitations) of optimization of control and making decision.

It is also important regards the random or stochastic factors of multiplicative and additive influence in models and criteria.

That is,

$$
\Lambda(\vec{a})=\int_{t_{0}}^{T} \tilde{u}\left(\alpha_{1}, \alpha_{2}, \alpha_{3}, \alpha_{4}, \ldots\right) \exp (-\theta t) d t \rightarrow \max _{\left\{\alpha_{i}\right\} \in \bar{\Omega}} .
$$

As a criterion in tasks similar to those in question, they usually take the objective function of maximizing the average worker's consumption in a temporary interval:

$$
\int_{0}^{T} \frac{C(t)}{L_{1}(t)+L_{2}(t)} \exp (-\theta t) d t \rightarrow \max ,
$$

where $\theta>0$ is the discount rate, which reflects the degree of preference over of future consumption real consumption. Note that criterion (16) is only the economic private criterion. That's why, social and environmental, innovation and other criteria of optimality are also needed integrally.

\section{Problems of Synthesis Control in Stochastic Systems}

Let's consider the task of optimal control synthesis in stochastic linear systems [18].

Under the phase state of the system we will understand the vector $x=\left(x_{1}, x_{2}, \ldots, x_{n}\right)$, where $x_{i}, i=1, \ldots, n$ is a set of data characterizing the $i$-th sector of the system. Suppose that all sectors are equipped with some control levers: $u=\left(u_{1}, u_{2}, \ldots, u_{n}\right)$.

Each of this parameters is a vector made up of numerical values of the indicators of various characteristics of dynamics system. Let $\left[\mathrm{t}_{0}, \mathrm{t}_{\mathrm{k}}\right]$ be the period of development of the system under consideration. We will use $\xi$ to denote the vector of some additional parameters that are either determined by way of forecasting using 
statistical system data or are constants.

Thus, the dependence of each of the variables $x_{i}, i=1, \ldots, n$ on the control variables $u_{i}$ of the states of the system and the vector of parameters is investigated $\xi$.

In particular, the linearization model of the system has the following form:

$$
\begin{aligned}
& \dot{x}(\xi, t)=A(\xi) x(\xi, t)+B(\xi) u(\xi, t), \\
& x(\xi, t) \in R^{n}, u(\xi, t) \in R^{m}, A(\xi) \in R^{n \times m}, B(\xi) \in R^{n \times m} ;
\end{aligned}
$$

where $A(\xi)=\left\lfloor A_{i j}(\xi)\right\rfloor, B(\xi)=\left\lfloor B_{i j}(\xi)\right\rfloor$ are matrices with parametric uncertainty; $x(\xi, t)=\left\lfloor x_{i}(\xi, t)\right\rfloor$ is the state of the system vector; $u(\xi, t)=\left\lfloor u_{i}(\xi, t)\right\rfloor$ is the vector of management; $\xi$ is the vector of stochastic processes. The task of synthesizing optimal control over a stochastic dynamic system is formulated as follows: to find the law of optimal control in the form [18]:

$$
u(\xi, t)=-L \hat{x}(\xi, t)
$$

and the target functionality for optimization (minimization) is given in the form:

$$
J=\int_{\Omega}\left\{\int_{0}^{t_{k}}\left(x^{T}(\xi, t) Q x(\xi, t)+u^{T}(\xi, t) R u(\xi, t)\right) d t\right\} p(\xi) d \xi .
$$

That is, upon averaging we arrive at the following criterion of optimal control:

$$
\bar{J}(u)=E\left[\int_{0}^{t_{k}}\left(x^{T}(\xi, t) Q x(\xi, t)+u^{T}(\xi, t) R u(\xi, t)\right) d t\right] \Rightarrow \min .
$$

In a simple case, we can use the linear observation equation in the form: $y(t)=H(t) x(t)+\eta(t)$. In this observation equation, $H(t)$ is a observation stochastic matrix which can be set for practical reasons, and $\eta(t)$ is a process of the "white noise" type, which can be set according to statistics data. In this case, in line with the separation principle, we must solve two independent tasks [18].

In the early writings of the first author, the problem of optimal evaluation (filtration) in multiplicative-additive blends was solved using the integral description of the filter. However, the problem of filtration can be conveniently solved also by using the filter of Kalman for the linear case and the filter of Stratonovich for the nonlinear right-hand side of the dynamics equation [18]. Estimates of the state are established as conditional means with the construction and solution of the dispersion non-linear equations of the Ricatti type. This gives the solution to the differential stochastic equation. It could be implemented in the form of the well known system with feedback on the density of the distribution of initial conditions. The obtained state estimates $\hat{x}(t)$ is used in solving the second problem, i.e. optimal control of the type $\hat{u}(t)=-L(t) \hat{x}(t)$. As noted above, the problem of optimal control is usually based on the Bellman's principle or the principle of maximum [18]. As a criterion, different quality functionals, as well as a vector of functionals, can be applied.

\section{Conclusions}

Based on the use of modern models, methods and information technologies for the forecasting of the state of nonlinear dynamics of socio-humanitarian, ecological and economic systems which was integrated into stochastic models of processes and objects suitable for systems of systemic crises have been developed and investigated. The aspect of integration of many domains and sectors of activity of modern socio-ecologicaleconomic systems with elements of humanitarian parameters and variables - as complex systems of the CEESH type $[25,26]$ that function and develop under diferent difficult conditions of crises and instability is considered. As a result of complex formalization one of the variants of the integral economic, ecological, social and innovation non-linear model of stochastic dynamics is received in the system of stochastic differential and functional equations. Resulted the models of capital dynamics, labor resources (both unqualified and qualified), dynamics of knowledge, technologies and education, dynamics of investments, consumption, natural resources, etc. It is presented as the most complete integrated stochastic social and ecologically oriented model of growth and development in the innovative economy.

The problem of forecasting of the state of a complex systems in the innovation economy based on the integral model in the phase space with observation equations, variants of the forecasting model, as well as the development of filters and algorithms for solving problems of synthesis of optimal control in stochastic systems in state space. 
The prospect of further research in this area is the conduct of experiments on computer and their widespread practical use. The development and research of criteria, methods and models of optimal control of man-made creation and objects of making decision systems on the basis of the proposed integral model in the state space are also promising.

\section{References}

[1] S.A., Ayvazyan; M.Yu., Afanase; V.A., Rudenko, "Some questions of specification of three-factor models of the company's production potential, taking into account intellectual capital", Applied Econometrics, vol. 3 (27), pp. 56-66, 2012.

[2] V., Babenko; N., Chebanova; N. Ryzhikova; S., Rudenko; N. Birchenko, "Research into the process of multi-level management of enterprise production activities with taking risks into consideration", EasternEuropean Journal of Enterprise Technologies, vol. 1, № 3 (91), pp. 4-126 2018. DOI: https://doi.org/10.15587/1729-4061.2018.123461

[3] Babenko, V., Nazarenko, O., Nazarenko, I., Mandych, O., "Aspects of program control over technological innovations with consideration of risks", Eastern-European Journal of Enterprise Technologies, vol. 3/4 (93), pp. 6-14, 2018. DOI: https://doi.org/10.15587/1729-4061.2018.133603

[4] Babenko, V., Romanenkov, Yu., Yakymova, L., Nakisko, A., "Development of the model of minimax adaptive management of innovative processes at an enterprise with consideration of risks", EasternEuropean Journal of Enterprise Technologies, vol. 4 (89), pp. 49-56, 2017. DOI: https://doi.org/10.15587/1729-4061.2017.112076

[5] Brock, W.A.; Hsieh, D., "Nonlinear Dynamics, Chaos and Instability," MIT Press, 1991.

[6] Galitsin, V.K.; Ramazanov, S.K., "Integral Stochastic Nonlinear Model of the Dynamics of an Innovative Economy," Scientific-Analytical Journal "Modeling and Information Systems in Economics", pp. 50-64, 2017.

[7] Grigorkiv, V.S., "Simulation of a Multisectoral Ecological-Economic System," Cybernetics and System Analysis, vol. 3, pp. 147-157, 1999.

[8] Heets, V.M.; Seminozhenko, V.P., "Innovative Prospects of Ukraine,” Kh.: Constant, 2006.

[9] Klebanova, T.S.; Kizima, N.A., "Models of estimation, analysis and forecasting of social and economic systems," monogr. Kh.: FOP Liborkina L.M., VD "INZHEK",2010.

[10] Kleiner, G.B., "System Economics and System-Oriented Modeling," Economics and Mathematical Methods, vol. 3, pp. 71-93, 2013.

[11] Kolemaev, V.A., "Economic-mathematical modeling. Modeling of Macroeconomic Processes and Systems," A Textbook. Moscow: UNITI-DANA, 2005.

[12] Krass, M.S.; Chuprynov, B.P., "Mathematical methods and models for masters of economics," study. Allowance. SPb.: Peter, 2006.

[13] Leontiev, V.; Ford, D., "Inter-industry analysis of the impact of the structure of the economy on the environment," Economics and mathematical methods, vol. 8(3), pp. 370-400, 1972.

[14] Lucas, R.E., "On the mechanics of economic development," Journal of Monetary Economics, vol. 22(1), pp. 3-42, 1988.

[15] Makarov, V.L.; Baktizin, A.R.; Baktizin N.V., "Computable model of knowledge economy," Economics and mathematical methods, vol. 45(1), pp. 70-82, 2009.

[16] Moiseev, A.N., "Optimal and balanced trajectories in models of economic growth with an endogenous form of STR. Actual issues of econometric and mathematical modeling in common," M.: TEIS, pp. 178190, 2004.

[17] N.N., Moiseev, "Mathematical problems of system analysis," Moscow: Nauka, 1981.

[18] Ostrem, K., "Introduction to the stochastic theory of management," Moscow: Mir, 1970.

[19] S.K., Ramazanov, "Forecasting the development of an innovative economy based on an integrated stochastic model of growth dynamics," pp. 146-153, 2017.

[20] Ramazanov, S.K., "Modeling of social-ecological-economic dynamics in an unstable environment," Information Sciences and Systems Science. Poltava: PUET, pp. 284-287, 2015. 
[21] Ramazanov, S.K.; Burbel, O.A.; Vitlinsky, V.V. and others, "Risks, security, crises and sustainable development in the economy: methodologies, models, methods of management and decision-making," Monograph. Ed. prof. S.K. Ramazanova. Lugansk: "Nulledzh", 2012.

[22] S.K., Ramazano; N.E., Rogoza; E.K., Musayeva, "Nonlinear models and analysis of complex systems," on-tutorial manual. Ed. prof. S.K. Ramazanova. Lugansk-Poltava: PUET, 2009.

[23] Ramazanov, S.K.; Nadyon, G.A.; Krishtal, N.I.; Stepanenko, O.P.; Timashova, L.A., "Innovative technologies of crisis management of economic systems," Monograph. Ed. prof. S.K. Ramazanova. Lugansk - Kiev: SNU named V. Dalya, 2009.

[24] Ramazanov, S.K.; Levasheva, L.W.; Stepanenko, O.P.; Timashova, L.A., Zakrzewski, J.J., "Innowacyjna technologie zarządzania antykryzysowego," Monografiya. Ed. prof. Ramazanova S.K. - WarszawaLugansk-Kiev: Reznikov V.S., 2011.

[25] S.K., Ramazanov; A.V. Sergienko, "Integral socio-ecological and economic stochastic model of dynamics of technogenic regional enterprise in the conditions of crisis," Monograph. Ed. prof. Solovyov V.N., pp. 89-108, 2015.

[26] Ramazanov, S.K., "Prediction and management of innovative economics based on the integral static model in phase space," pp. 207-215, 2018.

[27] P.M., Romer, "Increasing returns and long-run growth," Journal of Political Economy, vol. 94, pp. 10021037, 1986.

[28] R., Solou, "Theory of growth. Panorama of the economic thought of the end of the twentieth century," Ed. D. Greenway, M. Blini, I. Stewart, vol. 1. SPb.: Econ. Shk., pp. 479-506, 2002.

[29] V.I., Solovyov, "Economic-mathematical modeling of the software market," a monograph. GUU, M.: Vega-Info, 2009.

[30] Babenko, V.; Sidorov, V.; Koniaieva, Y.; Kysliuk, L., "Features and prospects of scientific and technical cooperation in the field of non-conventional renewable energy", Global J. Environ. Sci. Manage., 5(SI): 105-112, 2019. DOI: 10.22034/gjesm.2019.SI.12

[31] O., Tahvone; J., Kuuluvainen, "Economic growth, pollution, and renewable resources," Journal of Environmental Economics and Management, vol. 24, pp. 23 - 34, 1993.

[32] Babenko, V.; Perevozova, I.; Mandych, O.; Kvyatko, T.; Maliy, O.; Mykolenko, I., „World informatization in conditions of international globalization: factors of influence". Global. J. Environ. Sci. Manage., 5(SI): 172-179, 2019. DOI: 10.22034/gjesm.2019.SI.19

[33] J., Tsukui, Y., Murakami, "Turnpike optimality in input-output system-theory and application for planning," Amsterdam: North-Holland.

[34] Ya.Ya., Vagapova, "Modeling of economic growth taking into account environmental and social factors," M.: MAKS Press, 2007.

[35] Vorontsovsky, A.V.; Vyunenko, L.F., "Forecasting of economic development based on a stochastic model of economic growth taking into account the turning point," Vestnik SPbSU. Series 5. Economics, vol. 4, pp. 4-32, 2016. 